\section{Original article}

\title{
Prevalence of sexual dysfunction in new heterosexual attenders at a central London genitourinary medicine clinic in 1998
}

\author{
David Goldmeier, Ali Judd, Kate Schroeder
}

\begin{abstract}
Objective: To determine the prevalence of sexual dysfunction and dissatisfaction (SD) among new heterosexual attendees at a central London genitourinary medicine (GUM) clinic.

Methods: Consecutive new attendees seen by a single clinician were asked a probe question about SD in the previous year. A clinical interview followed a positive response to the probe question. Demographic information was obtained using standard clinic forms.

Results: $37 \%$ of 103 men and $20 \%$ of 100 women participants gave positive responses, and $24 \%$ of the men and $12 \%$ of the women wanted treatment for their problems.

Conclusions: Our results indicate a relatively high rate of SD in new GUM clinic attendees that is not currently being detected or managed. SD may lead to psychological problems, which can be reversed with appropriate treatment. The financial implications of such treatment are discussed. (Sex Transm Inf 2000;76:208-209)
\end{abstract}

Keywords: genitourinary medicine clinic; sexual dysfunction; London

\section{Introduction}

Genitourinary medicine (GUM) clinics in the United Kingdom traditionally treat sexually transmitted infections (STI), but are increasingly also taking on the role of managing patients with sexual dysfunction (SD), often as secondary or tertiary referrals. ${ }^{1}$ However, it is uncertain what proportion of patients attending "walk-in" GUM clinics also have SD. SD can lead to decreased quality of life and overt psychiatric illness, ${ }^{2-4}$ although evidence suggests that treatment improves both quality of life and psychological state. ${ }^{5}$ A previous study from our unit suggested that $24 \%$ of men and $9 \%$ of woman seen in a walk-in GUM clinic in London in 1996 suffered from significant SD. ${ }^{6}$ In that study SD was measured using a self administered questionnaire-the Golombok Rust Inventory of Sexual Satisfaction (GRISS). ${ }^{7}$ As the GRISS was validated for heterosexual couples, the derived rates in that study were for that population only.

In this present study we aimed to validate our previous study, our hypothesis being that there are indeed high rates of SD in patients presenting to our clinic. Our current method of assessment for SD was by screening patients with a standardised "probe question" followed by a clinical interview.

K Schroeder

Department of Social Science and Medicine, Imperial College School of Medicine, London W2 1PG

A Judd

Correspondence to: Dr Goldmeier, St Mary's Hospital, Jefferiss Wing, London W2 $1 \mathrm{NY}$ david@goldmeier. freeserve.co.uk

Accepted for publication 20 March 2000 took part. No patient refused to see DG or to take part in the study. All patients were asked a probe question, "Have you been dissatisfied with your sex life, or have you had any sexual problems over the last year?" Cases who answered "yes" to this question underwent a clinical interview (by DG) to obtain details of the exact nature of the sexual problem. Demographic details were obtained from all patients using standard clinic forms. The KC60 classification was used to record STI diagnoses for participants. Data from this study were compared with the total attendances at the Jefferiss Wing for 1998. The hospital's ethics committee gave approval for this study.

The statistical software package STATA 5.0 (Stata Corp, College Station, TX, USA) was used for all analyses. Differences in the distributions of different groups across continuous variables were assessed using the Mann-Whitney (MW) Z. Heterogeneity in distributions of different groups across categorical variables was assessed using the $\chi^{2}$ test. Exact binomial confidence intervals were calculated for proportions. All $\mathrm{p}$ values refer to the $\chi^{2}$ test unless otherwise stated.

\section{Results}

Table 1 depicts the characteristics of the study sample $(n=203)$ and all new heterosexual attenders at the Jefferiss Wing in 1998 $(n=9183)$. There were no statistical differences between the sample and all new attenders in terms of ethnic group or marital status. However, there were proportionally fewer females in the study sample than in the clinic population, and the median age of the study sample was slightly older than that for the clinic population ( 30 years $v 27$ years, $p<0.01$ ). The proportions of KC60 diagnoses were similar for both groups.

Similar percentages of males and females were recruited to this study and the previous 1996 study $\left(\chi^{2} 1 \mathrm{df}=0.01, \mathrm{p}=0.92\right)$. However, the populations differed in terms of ethnicity 
Table 1 Characteristics of the study sample and the clinic population in 1998

\begin{tabular}{|c|c|c|c|}
\hline Characteristic & $\begin{array}{l}\text { Sample (\%) } \\
(n=203)\end{array}$ & $\begin{array}{l}\text { Population (\%) } \\
(n=9183)\end{array}$ & p Value \\
\hline \multicolumn{4}{|l|}{ Sex } \\
\hline Female & $100(49.3)$ & $5212(56.8)$ & \\
\hline Male & $103(50.7)$ & $3971(43.2)$ & 0.03 \\
\hline \multicolumn{4}{|l|}{ Age } \\
\hline Median (range) & $30(17-74)$ & $27(8-68)$ & $M W<0.01$ \\
\hline \multicolumn{4}{|l|}{ Ethnicity } \\
\hline White & $106(54.1)$ & $5141(58.0)$ & \\
\hline Black & $50(25.5)$ & $1878(21.2)$ & \\
\hline Asian & $6(3.1)$ & $343(3.9)$ & \\
\hline Other & $34(17.3)$ & $1504(17.0)$ & 0.47 \\
\hline \multicolumn{4}{|l|}{ Marital status } \\
\hline Single & $127(64.1)$ & $6218(68.9)$ & \\
\hline Married/cohabiting & $54(27.3)$ & $2203(24.4)$ & \\
\hline Divorced/separated & $16(8.1)$ & $575(6.4)$ & \\
\hline Widowed & $1(0.5)$ & $35(0.4)$ & 0.52 \\
\hline \multicolumn{4}{|l|}{ KC60 “diagnosis"^ } \\
\hline Gonorrhoea & $3(1.5)$ & $200(2.2)$ & \\
\hline Herpes & $6(3.0)$ & $315(3.4)$ & \\
\hline Warts & $18(8.9)$ & $653(7.1)$ & \\
\hline C4 category† & $50(24.6)$ & $2289(24.9)$ & \\
\hline Vaginosis $\ddagger /$ balanitis & $33(16.3)$ & $2080(22.7)$ & \\
\hline Scabies & $3(1.5)$ & $98(1.1)$ & \\
\hline HIV testing & $35(17.2)$ & $2661(29.0)$ & \\
\hline Other untreated conditions & $37(18.2)$ & $1938(21.1)$ & \\
\hline Other treated conditions & $41(20.2)$ & $1631(17.8)$ & \\
\hline
\end{tabular}

Percentages add up to more than $100 \%$ as some patients had multiple "diagnoses."

$\star$ Defined as all new heterosexual attenders at the Jefferiss Wing.

†C4 category includes non-specific urethritis, chlamydia, and complicated chlamydial disease.

$\ddagger$ Includes trichomoniasis, bacterial vaginosis, and candidiasis.

(75\% white in $1996 v 54 \%$ white in $1998, \chi^{2} 1$ df $=18.3, \mathrm{p}<0.01)$, marital status $(81 \%$ single in $1996 v 64 \%$ single in $1998, \chi^{2} 1 \mathrm{df}=14.8, \mathrm{p}$ $<0.01$ ), and median age (27 years in $1996 v 30$ years in 1998, MW $\mathrm{Z}=3.0$, $\mathrm{p}<0.01)$.

Just over a third of males (38/103, 37\%, 95\% CI $28 \%-47 \%$ ) compared with a fifth of females $(20 / 100,20 \%, 95 \%$ CI $13 \%-29 \%)$ reported SD ( $\mathrm{p}<0.01)$. "Caseness" was also associated with ethnicity, with an average of $26 \%(50 / 190$, $95 \%$ CI 20\%-33\%) of white, black, and "other" participants being cases compared with $83 \%(5 / 6,95 \%$ CI $36 \%-100 \%)$ in Asian participants $(\mathrm{p}<0.01)$. However, caseness was not associated with age, marital status, or KC60 diagnosis.

Among women reporting SD, 50\% were diagnosed as having anorgasmia, 35\% decreased sexual desire, $20 \%$ arousal problems, $10 \%$ dissatisfaction, and $50 \%$ other problems. For men, $42 \%$ were diagnosed with erectile dysfunction, $18 \%$ dissatisfaction, $13 \%$ premature ejaculation, $11 \%$ retarded ejaculation, $8 \%$ decreased sexual desire, and $16 \%$ other problems. Nine women and three men received more than one SD diagnosis.

Twenty four per cent of men (25/103, 95\% CI $16 \%-34 \%)$ and $12 \%$ of women $(12 / 100$, $95 \%$ CI $6 \%-20 \%$ ) in the total sample were "cases" and requested treatment for their problem. All the female cases presented to the clinic with problems other than SD compared with $71 \%$ of the men $(\mathrm{p}<0.01)$.

\section{Discussion}

In this study $37 \%$ of men and $20 \%$ of women had SD. The sample was based on consecutive new attenders seen by one physician at a central London GUM clinic, and was representative of the wider clinic population in terms of ethnic group and marital status but not median age or sex. The lower proportion of females both in the study sample, and reporting sexual dysfunction, could be due to new female patients, and particularly those with sexual difficulties, opting not to see the male physician (DG) (this is a standard option in our clinic).

The SD rates in this study appear to be higher than those in our 1996 study, where dysfunction was measured using the GRISS. However, the GRISS asks patients to assess their sexual functioning "recently" whereas the probe question related to the previous year. Furthermore as discussed above, there were some differences in the sample populations of the two studies. None the less, the order of magnitude of the SD rates in our two studies is similar to other previous studies in both GUM clinics, ${ }^{8-10}$ and the wider population, both in the United Kingdom ${ }^{11}$ and the United States. ${ }^{12}$

Our results suggest that $24 \%$ of men and $12 \%$ of women attending a walk-in clinic for the first time have SD and would want treatment for this problem. These figures exclude referrals from other hospital departments (for example, diabetes clinics) and from general practitioners. These data have significant service and financial implications for GUM clinics. Currently our purchasers (and possibly most other GUM clinic purchasers in the United Kingdom) do not provide specific resources for patients with SD, although nearly half the UK GUM clinics recently surveyed already have dedicated SD clinics. ${ }^{1}$

It thus appears there is a relatively high rate of SD in new GUM clinic attendees that is not currently being detected or managed. Furthermore, SD has knock on implications in terms of consequent decreases in quality of life and depression. However these are preventable with appropriate treatment of the sexual problem.

Contributors: DG initiated this study, conducted all clinical interviews, and drafted the manuscript; AJ conducted the statistical analysis and interpretation and edited the manuscript; KS helped construct and initiate this study.

1 Keane FEA, Carter P, Goldmeier D, et al. The provision of psychosexual services by genitourinary medicine physicians in the United Kingdom. Int $\mathcal{F}$ STD AIDS 1997;8:402-4.

2 Aroujo AB, Durante R, Feldman HA, et al. The relationship between depressive symptoms and male erectile dysfunction; cross sectional results from the Massach

3 Shabsigh R, Klein LT, Seidman S, et al. Increased incidence of depressive symptoms in men with erectile dysfunction. Urology 1998;52:848-52.

4 Litwin MS, Nied RJ, Dhanani N. Health related quality of ife in men with erectile dysfunction. F Gen Intern Med 1998;13:159-66.

5 Wilke RJ, Yen W, Parkerson GR, et al. Quality of life effects of alprostadil therapy for erectile dysfunction: results of a trial in Europe and South Africa. Int $\mathcal{f} \operatorname{Imp}$ Res 1998;10:239-46.

6 Goldmeier D, Keane FEA, Carter P, et al. Prevalence of sexual dysfunction in heterosexual patients attending a central London genitourinary medicine clinic. Int $\mathcal{F} S T D$ AIDS 1997;8:803-6.

7 Rust J, Golombok S. The Golombok Rust Inventory of Sexual Satisfaction (GRISS). Windsor: NFER Nelson, Sexual
1986.
O'Gormar

8 O'Gorman EC, Bownes IT, Dinsmore WW. Sexual and marital therapy in STD clinic attenders. Int $\mathcal{F}$ STD AIDS 1995;5:63-8.

9 Frost DP. Recognition of hypochondiasis in a clinic for sexually transmitted diseases. Genitourin Med 1985;61: 133-7.

10 Catalan J, Bradley M, Gallwey J, et al. Sexual dysfunction and psychiatric morbidity in patients attending a clinic for sexually transmitted diseases. Br $\mathcal{F}$ Psychiatry 1981;138: 292-6.

11 Dunn KM, Croft PR, Hackett GI. Association of sexual problems with social, psychological and physical problems in men and women: a cross sectional population survey. $\mathcal{F}$ Epidemiol Comm Health 1999;54:144-8.

12 Laumann EO, Paik A, Rosen RC. Sexual dysfunction in the United States. Prevalence of predictors. FAMA 1999;281: $537-44$. 